\title{
Levantamento da fauna de abelhas (Hymenoptera, Apoidea) em um fragmento de Mata Atlântica, no município de Ubá, Minas Gerais
}

\section{Survey of the bee fauna (Hymenoptera, Apoidea) in an Atlantic Forest fragment at Ubá municipality, Minas Gerais state, Southeastern Brazil}

\author{
DOI: $10.46814 / 1 a j d v 3 n 5-038$
}

Recebimento dos originais: 01/05/2021

Aceitação para publicação: 31/06/2021

\author{
Ronaldo Vinícius-Silva \\ Biólogo, doutor em Botânica (UFV) \\ Instituição de atuação atual: Unidade de Pesquisa e Inovação em Campos Rupestres da Gerdau \\ E-mail: ronaldovsilva14@gmail.com \\ Nara Pessata Ferraz \\ Bióloga, especialista em Educação Ambiental (Centro Universitário Barão de Mauá - CBM) \\ Instituição de atuação atual: E. E. Padre Joãozinho \\ E-mail: narapessata@hotmail.com \\ Margarete do Valle Werneck \\ Bióloga, mestre em Biologia Celular e Estrutural (UFV) \\ Instituição de atuação atual: Faculdade Sudamérica \\ E-mail: guetewerneck@ hotmail.com
}

\section{RESUMO}

Realizou-se um levantamento da fauna de abelhas ocorrentes em um fragmento de Mata Atlântica no município de Ubá - MG. O estudo foi realizado em um período de 12 meses. Para a amostragem das espécies foram utilizadas armadilhas odoríferas em garrafas pet, armadilhas de nidificação e coletas em voo. Foram amostrados 40 indivíduos pertencentes a 13 espécies. Dentre essas, três consideradas sociais, uma primitivamente social e nove espécies de hábito solitário. Apesar de próximo à área urbana, a riqueza de espécie foi considerada alta. Novos estudos no município e em áreas adjacentes devem ser conduzidos com a finalidade de ampliar o conhecimento sobre as populações de abelhas da região e assim reunir dados que possam contribuir para a execução de estratégias de manejo visando à conservação desses polinizadores.

Palavras-Chave: abelhas, conservação, Mata Atlântica, polinizadores

\begin{abstract}
We surveyed the bee fauna in an Atlantic forest fragment at Ubá municipality, Minas Gerais state, southeastern Brazil. We study was conducted over a 12-month period. For species sampling, we used scent traps made with PET bottles, trap-nests, and targeted sweep netting. We sampled 40 individuals from 13 species. Three species are social, one is primitively social and nine are solitary. Although the sampling site is located near the urban perimeter, it showed high species richness. Further studies in the municipality and in adjacent areas must be conducted in order to increase knowledge of the bee population in the region, thus enabling the compilation of a dataset that might contribute with management practices aimed at the conservation of these important pollinators.
\end{abstract}


Keywords: Atlantic forest, bees, conservation, pollinators

\section{INTRODUÇÃO}

As abelhas pertencem à ordem Hymenoptera e assim como as vespas (Spheciformes) compõem a superfamília Apoidea. A diversidade apícola é estimada em cerca de 20.000 espécies, as quais são amplamente distribuídas em função da ocorrência das angiospermas (MICHENER, 2000). No Brasil são descritas aproximadamente 1.576 espécies, apesar de que se acredita que esse número seja subestimado e possa atingir cerca de 3.000 táxons pertencentes às famílias Andrenidae, Apidae, Colletidae, Halictidade e Megachilidade (SILVEIRA et al., 2002).

A respeito de seu hábito, é digno destacar que dentre as espécies atualmente descritas, há aquelas classificadas como solitárias e as reconhecidamente sociais. As abelhas solitárias constroem seu próprio ninho, tarefa efetuada pelas fêmeas, e geralmente não há contato com a prole. Diferentemente, as espécies sociais constroem colônias onde se podem observar separação por castas, divisão do trabalho, sobreposição de gerações, cooperação nas tarefas e alimentação progressiva das larvas (MICHENER, 1974).

A importância das abelhas pode ser atribuída, por exemplo, à apicultura e à meliponicultura, enfatizando a geração de empregos e renda. No entanto, a principal contribuição desses agentes está associada a sua atuação como polinizadores, sendo considerados fundamentais para a diversidade florística, equilíbrio de grande parte dos ecossistemas e manutenção de inúmeras culturas (MENEZESPEDRO; CAMARGO, 2000). Essa interação confere sucesso às plantas a partir da polinização cruzada, garantindo a elas uma importante adaptação evolutiva (COUTO; COUTO, 2002).

Apesar de sua relevante atuação para a manutenção dos ecossistemas, as populações de abelhas vêm sendo atingidas pela ação antrópica, principalmente através do desmatamento de áreas nativas. Nesse contexto, pode-se destacar a Mata Atlântica, bioma que historicamente tem sofrido com a perda de hábitat em decorrência da intervenção humana. Dentre os biomas brasileiros, este é o que menos se tem conhecimento sobre a fauna apícola (GONÇALVES; BRANDÃO, 2008). O inventário das espécies de abelhas é uma maneira de se conhecer a diversidade desses agentes, fato que contribui para o desenvolvimento de estratégias de manejo para a preservação desse importante grupo de polinizadores. Digno ressaltar que a proteção desses agentes colabora consequentemente para a manutenção do equilíbrio ecossistêmico.

No estado de Minas Gerais, a perda de áreas de Floresta Atlântica seguiu o mesmo padrão visualizado em todo o país. O município de Ubá, um dos mais importantes da Zona da Mata mineira, 
o qual se destaca atualmente pela força da indústria moveleira (FERNANDES; OLIVEIRA-JUNIOR, 2002), foi atingido pelo desmatamento principalmente em função de sua intensa produção de café e fumo em meados do século XIX. Esse processo ocasionou a substituição de áreas de mata nativa por lavouras e pastagens (VALVERDE, 1958). Atualmente o município conta com apenas 0,1\% de cobertura florestal, sendo considerado como área prioritária para projetos de conservação (FUNDAÇÃO COPPE/UFRJ, 2000).

Uma vez que o município de Ubá carece de estratégias para a conservação da pouca área de vegetação nativa registrada em sua faixa territorial, o conhecimento da diversidade de abelhas ocorrentes nos fragmentos presentes em seus limites geográficos seria um passo primordial nesse contexto, já que a ação desses polinizadores contribui para a manutenção desses remanescentes de Mata Atlântica. Sendo assim, o objetivo desse estudo é realizar o levantamento da fauna de abelhas em uma área com um remanescente de Floresta Atlântica, identificando as espécies com maior diversidade de indivíduos e consequentemente aquelas que mais contribuem para a polinização dos grupos vegetais que ali se desenvolvem.

\section{MATERIAL E MÉTODOS}

A área de realização da pesquisa corresponde ao espaço onde será construído o Campus da Universidade do Estado de Minas Gerais, no município de Ubá - MG, situado na rodovia Ubá - Ligação (21 ${ }^{\circ} ' 26.04$ " S e 42 57'31.49” W), com cerca de 38,5 ha. O clima da região é tropical AW, de acordo Köppen.

As coletas foram realizadas no período de março de 2010 a fevereiro de 2011, no horário das 09:00 às 14:00h. A captura das abelhas foi realizada com a utilização de rede entomológica. A procura de ninhos no interior da mata foi conduzida com o auxílio de barra de ferro e de facão para a abertura de trilhas. Durante o mês de setembro, foram distribuídas caixas-iscas, semelhantes às utilizadas por Witter et al. (2007) e iscas-bambu, adaptadas a partir da metodologia de Cordeiro (2009), na tentativa de captura de abelhas sociais e solitárias, respectivamente. Estas foram afixadas com arame em galhos de árvores e mourões de cerca, sendo que a região logo abaixo das armadilhas (referentes aos galhos e mourões) foi coberta com graxa para evitar o acesso de formigas (Figura 1).

A partir do mês de dezembro, foram utilizadas iscas aromáticas ( $\beta$-ionona, eugenol, cinamato de metila, salicilato de metila e vanilina) para a atração e posterior captura de abelhas solitárias da subtribo Euglossina. As armadilhas para a utilização dessas iscas foram confeccionadas com garrafas pet (2 L), de acordo com o mencionado por Ramalho (2006), e espalhadas a uma distância de 5 m uma das outras. Cada armadilha era montada a partir de quatro garrafas, sendo que em três delas utilizava- 
se apenas a região apical (funil). A quarta garrafa compunha a base da armadilha e, na sua região mediana, foram feitos três furos onde se encaixavam e colavam os três funis (sem as suas respectivas tampas) os quais funcionavam como entrada para as abelhas. Pendurado à tampa da garrafa base estava um chumaço de algodão embebido com a isca aromática.

Apesar de o foco das coletas ter sido concentrado no fragmento de mata nativa, o entorno deste englobava outros tipos de vegetação e nestes também foram distribuídas armadilhas e realizadas buscas por ninhos, uma vez que a área de forrageio das abelhas é ampla e estas poderiam prontamente nidificar e ir à busca de recompensas florais em locais que extrapolassem os limites do fragmento em questão. Além do fragmento de mata nativa (Mata Atlântica), o local era composto por uma plantação de Pinus sp., uma pequena porção com Eucaliptus sp., além de uma área de pastagem. Com vistas a facilitar o esforço amostral, o local de estudo foi dividido em quatro setores: A e B (área de pastagem), C (Pinus sp. e Eucaliptus sp.) e D (Mata Nativa) (Figura 2).

Todos os indivíduos coletados foram sacrificados em câmaras mortíferas contendo algodão e acetato de etila ou álcool etílico e em seguida encaminhados à Universidade Federal de Viçosa (UFV) para identificação.

\section{RESULTADOS E DISCUSSÃO}

Os esforços de coleta resultaram na amostragem de 40 indivíduos pertencentes a 13 espécies de abelhas (Tabela 1). Dentre essas, três são consideradas sociais: Trigona spinipis (Fabricius, 1793), Tetragona clavipes (Fabricius, 1804) e Apis mellifera (Linnaeus, 1758), sendo as duas primeiras pertencentes ao grupo dos meliponíneos. Para cada uma dessas espécies, também foram encontrados seus respectivos ninhos. O ninho de $T$. spinipis foi encontrado na área de pastagem (setor A) e o de $T$. clavipes, no interior da mata nativa (setor D). A respeito de A. mellifera, foram encontrados dois ninhos construídos em cupinzeiros, ambos localizados na 


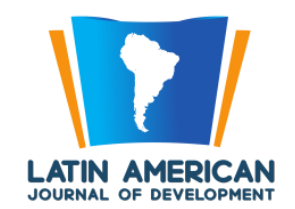

Figura 1 - Coleta de abelhas em área com fragmento de Mata Atlântica em Ubá - MG. A. Caminhamento em busca de espécies em forrageio. B. Coleta de espécies em forrageio através de rede entomológica. C. Abertura de trilhas em área de mata a procura de ninhos. D. Distribuição de iscas bambu para a nidificação de abelhas solitárias. E-F. Distribuição de caixas isca para a nidificação de abelhas sociais

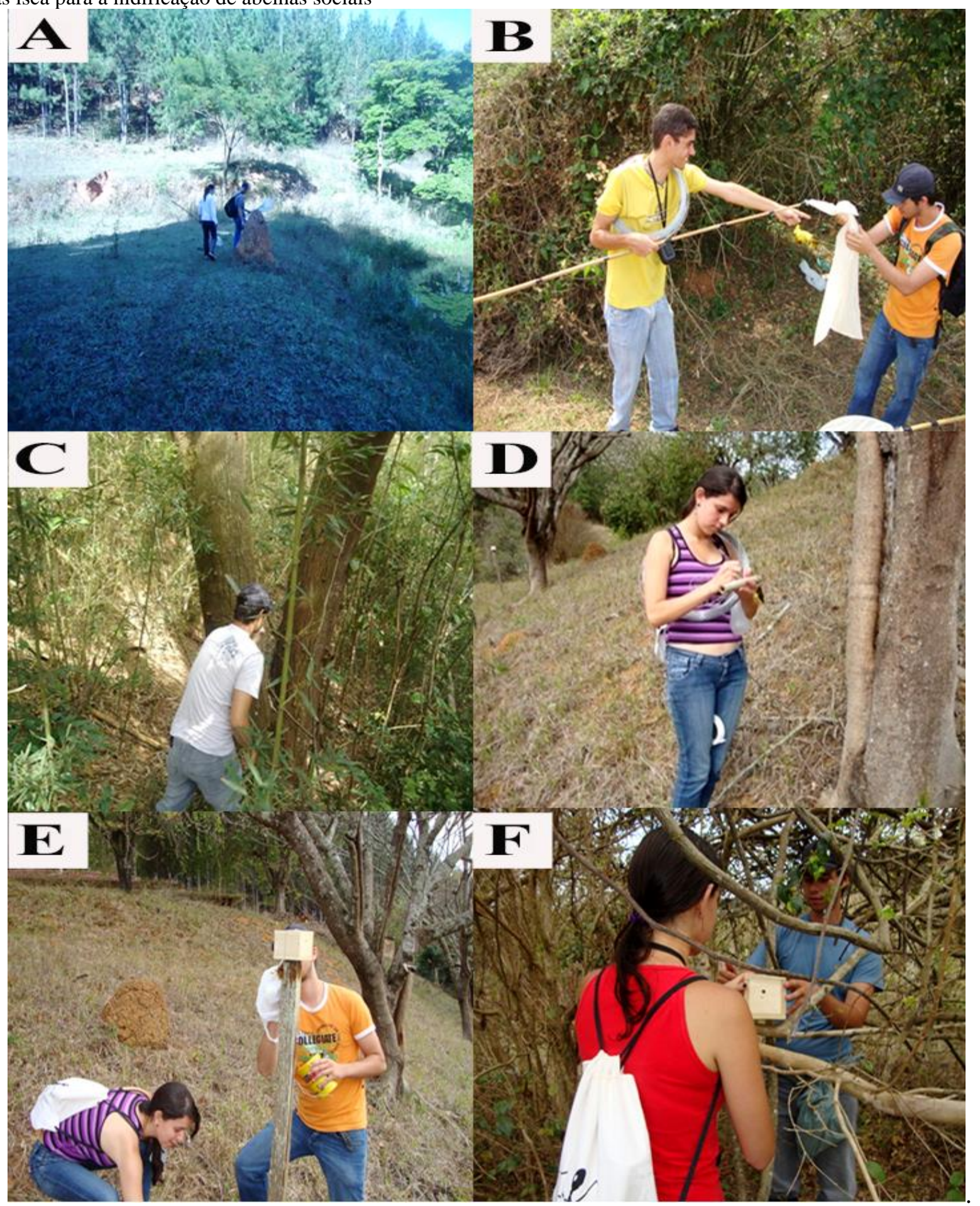




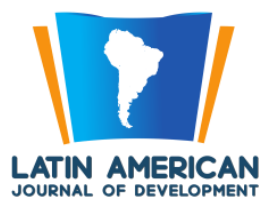

Figura 2 - Áreas de amostragem. A. Porção com Pinus sp. B. Porção com Eucaliptus sp. C. Pastagem. D. Fragmento de Mata Atlântica.
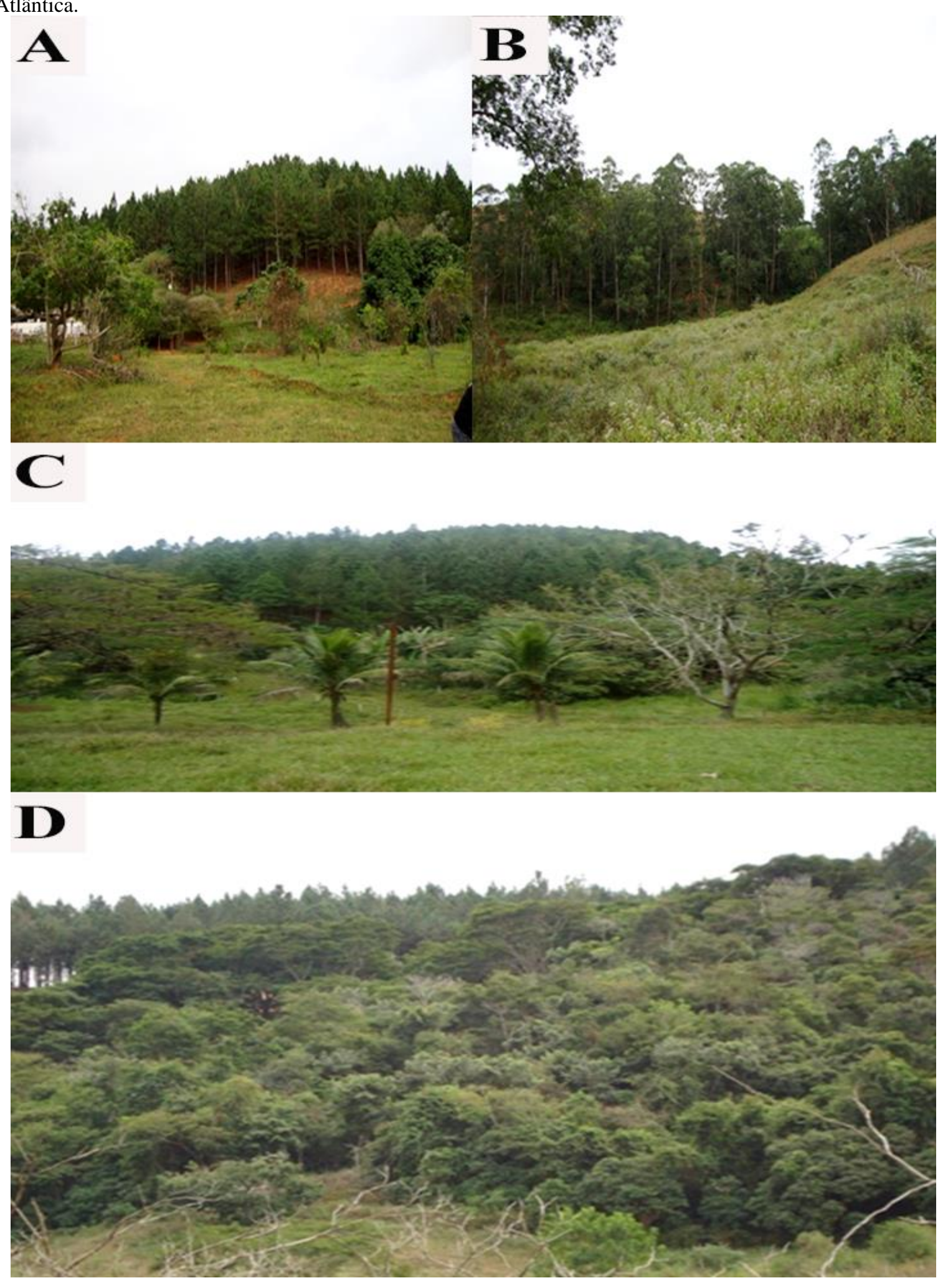

área de pastagem (setor B). Em relação ao restante de táxons inventariados, Bombus morio (Swederus, 1787) é considerada primitivamente social e as demais são solitárias. As abelhas de hábito 
solitário foram, na sua maioria, identificadas a nível específico, algumas a nível genérico e uma das espécies foi possível apenas a classificação da tribo, que, no caso, refere-se à Tapinotaspidini.

As abelhas sociais foram coletadas enquanto sobrevoavam as flores e, no caso de $T$. clavipes, a captura foi realizada, também, próximo à entrada do ninho. Os indivíduos das duas espécies de meliponíneos foram coletados, assim como os de A. mellifera, apenas com o auxílio de rede entomológica. O número de indivíduos amostrados, bem como a quantidade de ninhos encontrados, de A. mellifera foi superior em relação à $T$. spinipis e $T$. clavipes.

Apis mellifera é uma espécie exótica que foi introduzida no Brasil provinda do continente europeu, mais especificamente de nações como Portugal, Espanha, Alemanha e Itália. Posteriormente, indivíduos dessa mesma espécie foram trazidos para o Brasil oriundos da África do Sul (PEREIRA et al., 2003). Esses indivíduos apresentam algumas características como, por exemplo, alta habilidade de dispersão, elevada frequência na formação de enxames e uma baixa seletividade de locais para nidificação, que os caracterizam como insetos de maior densidade (SCHMIDT; HURLEY, 1995), fato evidenciado no presente estudo. Importante também destacar que essa espécie apresenta uma ampla distribuição (MICHENER, 2000). No Brasil, pesquisas realizadas por Faria-Mucci et al. (2003) e d'Avila e Marchini (2008) (região sudeste), Gonçalves e Melo (2005) (região sul) e Santos et al. (2004) (região norte) apontaram A. mellifera como a espécie mais generalista. Em estudos conduzidos por Pigozzo (2004) (região nordeste) e Santiago et al. (2009) (região Centro Oeste), esta foi considerada a espécie com maior riqueza de indivíduos.

Tabela 1. Espécies amostradas em área com remanescente de Mata Atlântica no município de Ubá, Minas Gerais. Classificação de acordo com Roig-Alsina e Michener (1993) e Alexander e Michener (1995).

\begin{tabular}{|c|c|c|c|c|c|}
\hline Espécie & Indivíduos & Família & Subfamília & Tribo & Subtribo \\
\hline $\begin{array}{c}\text { Apis mellifera (Linnaeus, } \\
1758 \text { ) }\end{array}$ & 10 & Apidae & Apinae & Apini & Apina \\
\hline $\begin{array}{c}\text { Bombus morio (Swederus, } \\
\text { 1787) }\end{array}$ & 04 & Apidae & Apinae & Apini & Bombina \\
\hline $\begin{array}{c}\text { Centris analis (Fabricius, } \\
1804)\end{array}$ & 02 & Apidae & Apinae & Centridini & - \\
\hline Centris sp. & 01 & Apidae & Apinae & Centridini & - \\
\hline $\begin{array}{l}\text { Epicharis (Epicharoides) } \\
\text { picta (Smith, 1874) }\end{array}$ & 01 & Apidae & Apinae & Centridini & - \\
\hline Euglossa sp. & 01 & Apidae & Apinae & Apini & Euglossina \\
\hline $\begin{array}{c}\text { Eulaema cingulata (Fabricius, } \\
1804)\end{array}$ & 03 & Apidae & Apinae & Apini & Euglossina \\
\hline $\begin{array}{c}\text { Eulaema nigrita (Lepeletier, } \\
1841 \text { ) }\end{array}$ & 03 & Apidae & Apinae & Apini & Euglossina \\
\hline $\begin{array}{c}\text { Trigona spinipis (Fabricius, } \\
\text { 1793) }\end{array}$ & 06 & Apidae & Apinae & Apini & Meliponina \\
\hline $\begin{array}{l}\text { Tetragona clavipes } \\
\text { (Fabricius, 1804) }\end{array}$ & 05 & Apidae & Apinae & Apini & Meliponina \\
\hline
\end{tabular}




\begin{tabular}{|c|c|c|c|c|c|}
\hline Tetrapedia sp. & 01 & Apidae & Apinae & Tetrapediini & - \\
\hline - & 01 & Apidae & Apinae & Tapinotaspidini & - \\
\hline $\begin{array}{c}\text { Xylocopa frontalis (Olivier, } \\
1789 \text { ) }\end{array}$ & 02 & Apidae & Xylocopinae & Xylocopini & - \\
\hline
\end{tabular}

A quantidade de espécies de meliponíneos amostrada foi relativamente baixa. Isto pode estar relacionado ao fato de que a mata nativa presente na área de estudo não é muito extensa, e segundo Viana e Melo (1987), a fragmentação de ecossistemas acarreta uma diminuição de recursos para esses polinizadores, o que culmina com um decréscimo na quantidade de espécies e indivíduos. $\mathrm{O}$ desmatamento, o qual gera essa fragmentação das áreas nativas, reduz os locais para nidificação e também as fontes de alimento para essas abelhas (BRONW; OLIVEIRA, 2014). Outro fator a se ressaltar sobre essa questão é a presença de A. mellifera no local. De acordo com Roubik et al. (1986), a espécie exótica compete fortemente por alimento e isso pode prejudicar a expansão das abelhas nativas brasileiras.

As abelhas solitárias foram capturadas com rede entomológica enquanto forrageavam ou a partir das armadilhas com a utilização de iscas odoríferas. Viana et al. (2001) em seu estudo observou, a exemplo dos resultados aqui expostos, uma predominância das abelhas de hábito solitário em relação às sociais. $\mathrm{O}$ presente estudo amostrou quatro tribos compostas exclusivamente por espécies solitárias (Centridini, Tetrapediini, Tapinotaspidini e Xylocopini), além das espécies da subtribo Euglossina (tribo Apini), que também são caracterizadas por esse hábito. Essa maior diversidade de abelhas solitárias pode estar associada ao fato de que este grupo compreende $85 \%$ do total de abelhas existentes (MICHENER, 2000).

Dentre as iscas odoríferas utilizadas, apenas eugenol, vanilina e salicilato de metila obtiveram sucesso na atração de abelhas solitárias. As abelhas atraídas por esses compostos são as pertencentes à subtribo Euglossina, também conhecidas como abelhas das orquídeas. As iscas atraem geralmente os machos, os quais naturalmente visitam espécies de orquídeas para a coleta de fragrâncias florais (DRESSLER, 1982). Presume-se que essas fragrâncias possam funcionar como sinais químicos e estejam associados a comportamento de corte ou à territorialidade (DRESSLER, 1982).

Em relação às caixas iscas e às iscas bambu, nenhuma delas foi utilizada por espécies sociais (caixas-iscas) ou solitárias (iscas-bambu) para a formação de colônias ou nidificação. Em relação às iscas bambus, Viana et al. (2001), Cordeiro (2009) e Mesquita (2009) também as utilizaram para captura de abelhas solitárias e obtiveram sucesso. No entanto, destaca-se que o período de estudos com essas iscas foi maior, variando entre um e dois anos, diferentemente do presente trabalho onde estas foram dispostas em campo por apenas cinco meses. 
Outro fator importante de se ressaltar diz respeito à possibilidade das abelhas solitárias observadas e capturadas na área de estudo estarem apenas transitando no local a procura de alimento (TSCHARNTKE et al., 1998). Provavelmente essas espécies forrageavam na área em busca de recursos florais enquanto nidificavam em áreas adjacentes ao local onde a presente pesquisa foi desenvolvida. Por fim, o insucesso observado em relação a essas armadilhas também pode relacionarse à altura em que elas foram afixadas nos suportes (ca. 1,5-2m). Frankie et al. (1998) capturaram abelhas com armadilhas a 2,5 m do solo e Morato (2001) coletou esses polinizadores com iscas dispostas a uma altura de 8-15m do chão. Assim, as abelhas inventariadas na área de estudo podem ter preferência por nidificação em estratos com uma altura superior ou inferior àquela correspondente às armadilhas distribuídas.

As caixas-iscas foram dispostas, a exemplo das iscas-bambu, a uma altura entre 1,5-2m do solo. Segundo Oliveira et al. (2009), esse fator pode ser preponderante no sucesso da ocupação dos ninhos, pois algumas espécies podem apresentar preferência por alturas diferentes para enxamear. Os mesmos autores conduziram experimentos com esse tipo de isca para atração de meliponíneos em época semelhante à de condução do presente estudo, obtendo sucesso principalmente nos meses de setembro a fevereiro, devido à maior disponibilidade de recursos para as abelhas. Porém, eles enfatizam que um fator preponderante para o processo de enxameagem é a presença de um número considerável de colônias desses polinizadores no local, situação não observada na área de desenvolvimento desta pesquisa, onde foram encontrados apenas dois ninhos de abelhas nativas.

De acordo com o Instituto Nacional de Pesquisas Espaciais - INPE (2009), Minas Gerais possui atualmente ca. 9,68\% de Mata Atlântica, sendo que este percentual já atingiu ca. $46 \%$ da área total do estado. No município de Ubá, a área de Mata Atlântica compreende apenas 0,1\% de seu território (FUNDAÇÃO COPPE/UFRJ, 2000). Essa redução se deve à intensa atividade de exploração e desmatamento neste bioma. Esse processo acarreta a fragmentação de áreas nativas, anteriormente contínuas, constituindo, atualmente, ilhas de vegetação (VIANA; MELO, 1987; SILVEIRA et al., 2002). Segundo Kerr et al. (1994), esse fato compromete o fluxo gênico entre populações de abelhas ocorrentes em áreas próximas, culminando com a perda de sua variabilidade genética.

Considerando que a área de vegetação nativa do município é reduzida e que a área onde foi desenvolvida a pesquisa é composta por apenas um pequeno fragmento de Mata Atlântica, circundado por uma porção de Pinus sp. e Eucaliptus sp., justifica-se a pouca disponibilidade de recursos atrativos para populações de abelhas provenientes de fragmentos vizinhos, o que pode comprometer o fluxo gênico entre as espécies. D’ Ávila e Marchini (2008) realizaram um levantamento da fauna de abelhas em uma área nativa na cidade de Itirapina (SP) na qual perceberam que os resultados obtidos foram 
consideravelmente inferiores em relação a trabalhos realizados anteriormente com áreas de tamanhos similares. Essa diferença foi atribuída, principalmente, à presença de Pinus sp. e Eucaliptus sp. próximos ao local, sendo estas, espécies pouco atrativas ao forrageamento de abelhas.

Por outro lado, o fluxo gênico entre as populações de abelhas pode ser intensificado se considerarmos o raio de voo desses polinizadores. As abelhas solitárias podem atingir uma distância de voo de aproximadamente 150 a 600 m (GATHMANN; TSCHARNTKE, 2002). Já os Meliponíneos podem ter o seu raio de voo associado ao seu tamanho, sendo que quanto maior o indivíduo, maior será a distância percorrida (GREENLEAF, 2007). Nogueira-Neto (1997) estimou a distância percorrida para o forrageamento de algumas espécies de Meliponíneos como: Tetragonisca angustula (Latreille, 1811) (500m), Scaptotrigona postica (Latreille, 1811) (750m) e Melipona quadrifasciata (Lepeletier, 1836) $(2.500 \mathrm{~m})$. Esses resultados nos permitem ponderar que, mesmo se tratando de um fragmento pequeno e com poucas áreas nativas vizinhas, o local de estudo pode apresentar um fluxo gênico considerável quando se tem um raio de forrageio variável entre espécies de abelhas.

A preservação de remanescentes de vegetação nativa é essencial para a conservação desses polinizadores, já que essas áreas possuem fontes de alimento e sítios para nidificação. Uma vez extintas, essas espécies podem causar um problema ecológico de enormes proporções, visto que elas são responsáveis pela polinização de 80 a $90 \%$ das plantas nativas do Brasil, dependendo do bioma (PEREIRA, 2005). Uma estratégia está relacionada a iniciativas de reflorestamento do local, sendo que, se tratando da Mata Atlântica, é interessante o plantio de árvores típicas do bioma e que, ao mesmo tempo, tenham um grande poder atrativo para abelhas, ou seja, sejam fornecedoras de recursos para estes polinizadores.

Assim como é importante a preservação da vegetação, é interessante a utilização de técnicas que visem à preservação direta da população de abelhas do local. Tratando-se de espécies sociais, uma alternativa muito utilizada é o manejo racional das colônias. Essa técnica de utilização de caixas de madeira é uma boa estratégia para a atração de enxames. No interior dessas caixas, é colocada uma pequena quantidade de cerume e resina para a atração de novas abelhas (CAMPOS; PERUQUETTI, 1999). Assim, esses ninhos-iscas proporcionarão um aumento das colônias, auxiliando na conservação dessas espécies. No caso das abelhas solitárias, um tipo de técnica muito utilizada consiste no uso de colmos de bambus, distribuídos ao longo da área. Essa ação aumenta os sítios de nidificação para as espécies e, em longo prazo, pode ser uma eficiente técnica para o aumento das populações.

\section{CONSIDERAÇÕES}


Em virtude de a área de estudo apresentar um pequeno fragmento de vegetação nativa, o número de espécies de abelhas amostrado foi significativo, uma vez que esses insetos têm sofrido consideravelmente com a perda de hábitat em função da intensa fragmentação dos ecossistemas. Considerando que Ubá possui pouquíssima cobertura vegetal nativa, é recomendado que outros inventários da guilda de abelhas possam ser realizados em outros remanescentes de Mata Atlântica do município e até mesmo em municípios vizinhos. Assim, será possível conhecer de maneira mais ampla a diversidade de abelhas ocorrentes na região, obter informações mais concisas sobre a possibilidade de fluxo gênico entre fragmentos vizinhos e de fato propor e executar estratégias que visem a um manejo racional desses polinizadores, contribuindo para o aumento de suas populações.

\section{AGRADECIMENTOS}

Os autores agradecem à Universidade do Estado de Minas Gerais - Campus Ubá, pela oportunidade e pelo suporte durante a realização da pesquisa e à Fundação de Amparo à Pesquisa do Estado de Minas Gerais (FAPEMIG) pelo apoio financeiro através da concessão das bolsas de Iniciação Científica aos dois primeiros autores deste estudo. Nós também agradecemos aos colegas Victor Ribeiro Urgal e Cristiano Albano pelo auxílio nos trabalhos de campo; ao Professor Dr. Lúcio Antônio de Oliveira Campos pelo apoio e por nos permitir acesso ao Apiário da Universidade Federal de Viçosa e ao Dr. Hugo de Azevedo Werneck, pela colaboração durante a execução da pesquisa e pela contribuição na identificação das espécies. 


\section{REFERÊNCIAS}

ALEXANDER, B. A.; MICHENER, C. D. Phylogenetic studies of the families of short-tongued bees (Hymenoptera: Apoidea). The University of Kansas Science Bulletin, v. 55, p.377-424, 1995.

BROWN, J. C.; OLIVEIRA, M. L. The impact of agricultural colonization and deforestation on stingless bee (Apidae: Meliponini) composition and richness in Rondônia, Brazil. Apidologie, v. 45, p.172-188, 2014.

CAMPOS, L. A. O.; PERUQUETTI, R. C. Biologia e criação de Abelhas sem ferrão. Viçosa: Imprensa Universitária, 1999.

CORDEIRO, G. D. Abelhas solitárias nidificantes em ninhos armadilha em quatro áreas de Mata Atlântica do Estado de São Paulo. 2009. 84f. Dissertação (mestrado em entomologia) - Faculdade de Filosofia, Ciências e Letras de Ribeirão Preto, Universidade de São Paulo, Ribeirão Preto, 2009.

COUTO, R. H. N.; COUTO, L. A. Apicultura: manejo e produtos. 2 ed. Jaboticabal: FUNEP, 2002.

D'AVILA, M.; MARCHINI, L. C. Análise faunística de himenópteros visitantes florais em fragmento de cerradão em Itirapina, SP. Ciência Florestal, v. 18, n.2, p.271-279, 2008.

DRESSLER, R. L. Biology of the Orchid Bees (Euglossini). Annual Review of Ecology and Systematics, v. 13, p.373-394, 1982.

FARIA-MUCCI, G. M.; MELO, M. A.; CAMPOS, L. A. O. A fauna de abelhas (Hymenoptera, Apoidea) e plantas utilizadas como fontes de recursos florais, em um ecossistema de campos rupestres em Lavras Novas, Minas Gerais, Brasil In: MELO, G.A.R.; ALVES-DOS-SANTOS, I. (eds.). Apoidea Neotropica: Homenagem aos 90 anos de Jesus Santiago Moure. Criciúma: Unesc, 2003, p.241-256.

FRANKIE, G. W.; VINSON, S. B.; RIZZARDI, M. A.; GRISWOLD, T. L.; O'KEEFE, S.; SNELLING, R. R. Diversity and abundance of bees visiting a mass flowering tree species in disturbed seasonal dry forest, Costa Rica. Journal of the Kansas Entomological Society, v. 70, n. 4, p.281-296, 1998.

FERNANDES, C. L. L.; OLIVEIRA-JUNIOR, R. H. Cluster no setor moveleiro: um estudo das potencialidades da região de Ubá (MG). In: Seminário sobre a Economia Mineira, 10, 2002, Belo Horizonte, MG, Anais...Belo Horizonte: CEDEPLAR, 2002, p.1-26.

FUNDAÇÃO COPPE/UFRJ. Projeto Preparatório para o Gerenciamento dos Recursos Hídricos do Paraíba do Sul - RJ: programa de investimentos em Minas Gerais - Controle de Erosão. Relatório PPG-RE-021-R0. Rio de Janeiro: MMA/SRH/EIVAP/UNESCO/COPPE-UFRJ. Lab. Hidrologia, 2000.

GATHMANN, A.; TSCHARNTKE, T. Foraging ranges of solitary bees. Journal of Animal Ecology, v. 71, n. 5, p.757-764, 2002.

GONÇALVES, R. B.; BRANDÃO, C. R. F. Diversidade de abelhas (Hymenoptera, Apidae) ao longo de um gradiente latitudinal na Mata Atlântica. Biota Neotropica, v. 8, n. 4, p. 51-61, Out./Dez. 2008. 
GONÇALVES, R. B.; MELO, G. A. R. A comunidade de abelhas (Hymenoptera, Apidae s. 1.) em uma área restrita de campo natural no Parque Estadual de Vila Velha, Paraná: diversidade, fenologia e fontes florais de alimento. Revista Brasileira de Entomologia, v.49,n. 4, p.557-571, 2005.

GREENLEAF, S. S. Bee foraging ranges and their relationship to body size. Oecologia, v. 153, n. 3, p.589-596, 2007.

INPE. INPE e SOS Mata Atlântica divulgam dados do Atlas dos remanescentes florestais. 2009. Disponível em: < http://www.inpe.br/noticias/noticia.php?Cod_Noticia=1834> Acesso em: 14 Mar. 2011.

KERR, W. E.; NASCIMENTO, V. A.; CARVALHO, G. A. Há salvação para os meliponíneos? In: Encontro de Abelhas de Ribeirão Preto, 1, 1994, Ribeirão Preto, SP, Anais...Ribeirão Preto: Universidade de São Paulo, Faculdade de Filosofia, Ciências e Letras de Ribeirão Preto, 1994, p.6065 .

MENEZES-PEDRO, S. R.; CAMARGO, J. F. M. Biodiversidade do estado de São Paulo: síntese de conhecimento ao final do século XX. Apoidea, Apiformes. In: BRANDÃO, C. R. F. e CANCELLO, E. M. Invertebrados Terrestres. São Paulo: FAPESP, 2000. p. 193-211.

MESQUITA, T. M. S. Diversidade de abelhas solitárias (Hymenoptera, Apoidea) que nidificam em ninhos-armadilha em áreas de Cerrado, MG. 2009. 43f. Dissertação (mestrado em Ecologia e Conservação de Recursos Naturais) - Universidade Federal de Uberlândia, Uberlândia, 2009.

MICHENER C. D. The Bees of the World. Baltimore: The Johns Hopkins University Press, 2000.

MICHENER, C. D. The social behavior of the bees: a comparative study. Cambridge: Harvard University Press, 1974.

MORATO, E. F. Efeitos da fragmentação florestal sobre vespas e abelhas solitárias na Amazônia Central. II. Estratificação vertical. Revista Brasileira de Zoologia, v. 18, n. 3, p.737-747, 2001.

NOGUEIRA-NETO, P. Vida e criação de abelhas indígenas sem ferrão. São Paulo: Nogueirapis, 1997.

OLIVEIRA, R. C.; MENEZES, C.; SILVA, R. A. O.; SOARES, A. E. E.; IMPERATRIZ-FONSECA, V. L. Como obter enxames de abelhas sem ferrão na natureza. Mensagem Doce, v. 100, p.34-39, 2009.

PEREIRA, F. M. Abelhas sem ferrão a importância da preservação. 2005. Disponível em: < https://www.paginarural.com.br/artigo/1185/abelhas-sem-ferrao-a-importancia-da-preservacao> Acesso em: 10 Mar. 2011.

PEREIRA, F. M.; LOPES, M. T. R.; CAMARGO, R. C. R.; VILELA, S. L. O. Sistema de Produção de Mel. Teresina: Embrapa Meio-Norte, 2003.

PIGOZZO, C. M. Organização das comunidades locais de Apoidea em uma área de Caatinga, Canudos - Ba. 2004. 86f. Dissertação (de mestrado em Ecologia e Biomonitoramento) - Instituto de Biologia, Universidade Federal da Bahia, Salvador, 2004. 
RAMALHO, A. V. Comunidades de abelhas Euglossini (Hymenoptera; Apidae) em remanescentes de Mata Atlântica na bacia do Rio São João, RJ. 2006. 67f. Dissertação (mestrado em Ecologia e Recursos Naturais) - Centro de Biociências e Biotecnologia, Universidade Estadual do Norte Fluminense, Campos dos Goytacazes, 2006.

ROIG-ALSINA, A.; MICHENER, C. D. Studies of the phylogeny and classification of long-tongued bees (Hymenoptera: Apoidea). The University of Kansas Science Bulletin, v. 55, p.123-173, 1993.

ROUBIK, D. W.; MORENO, J. E.; VERGARA, C.; WITTMANN, D. Sporadic food competition with the African honey bee: projected impact on Neotropical social bees. Journal of Tropical Ecology, $\mathrm{v}$. 2, p. 97-111, 1986.

SANTIAGO, L. R.; BRITO, R. M.; MUNIZ, T. M. V. L.; OLIVEIRA, F. F.; FRANCISCO, F. O. A fauna apícola do Parque Municipal da Cachoeirinha (Iporá, GO). Biota Neotropica, v. 9, n. 3, p.393397, 2009.

SANTOS, F. M.; CARVALHO, C. A. L.; SILVA, R. F. Diversidade de abelhas (Hymenoptera: Apoidea) em uma área de transição Cerrado-Amazônia. Acta Amazônica, v. 34, n. 2, p.319-328, 2004.

SCHMIDT, J. O.; HURLEY, R. Selection of nest cavities by Africanized and European honey bees. Apidologie, v. 26, p.467-475, 1995.

SILVEIRA, F. A.; MELO, G. A. R.; ALMEIDA, E. A. (Ed). Abelhas Brasileiras: sistemática e Identificação. Belo Horizonte: Fundação Araucária, 2002.

TSCHARNTKE, T.; GATHMANN, A.; STEFFAN-DEWENTER, I. Bioindication using trap-nesting bees and wasps and their natural enemies: community structure and interactions. Journal of Applied Ecology, v. 35, p.708-719, 1998.

VALVERDE, O. Estudo regional da Zona da Mata de Minas Gerais. Revista Brasileira de Geografia, v. 20, n. 1, p.1-82, 1958.

VIANA, L. S.; MELO, G. A. R. Conservação de abelhas. Informe Agropecuário, v. 13, n. 149, p.2326, 1987.

VIANA, B. F.; SILVA, F. O.; KLEINERT, A M. P. Diversidade e sazonalidade de abelhas solitárias (Hymenoptera: Apoidea) em dunas litorâneas no nordeste do Brasil. Neotropical Entomology, v. 30, p.245-251, 2001.

WITTER, S.; BLOCHTEIN, B.; ANDRADE, F.; WOLFF, L. F.; IMPERATRIZ-FONSECA, V. L. Meliponicultura no Rio Grande do Sul: Contribuição sobre a biologia e conservação de Plebeia nigriceps (Friese, 1901) (Apidae, Meliponini). Bioscience Journal, v.23, p.134-140, Nov. 2007. 